\title{
Management of Traumatic Joint Dislocations in Irrua
}

\author{
Edwin Omon Edomwonyi, Osita Chizoba Nwokike, John Enekele Onuminya \\ Department of Orthopaedics and Traumatology, Irrua Specialist Teaching Hospital, Irrua, Nigeria \\ Email: edwinedomwonyi@rocketmail.com
}

Received 1 February 2015; accepted 6 March 2015; published 11 March 2015

Copyright (C) 2015 by authors and Scientific Research Publishing Inc.

This work is licensed under the Creative Commons Attribution International License (CC BY). http://creativecommons.org/licenses/by/4.0/

\section{(c) (i) Open Access}

\begin{abstract}
Aim: To elucidate the pattern of presentation and management of traumatic major joint dislocations as seen in Irrua Specialist Teaching Hospital. Method: A five-year retrospective review of 44 cases in 43 patients. Data were retrieved from the Medical Records Department of the hospital. Results: Forty-four cases of traumatic dislocations were reviewed in 43 patients. Male to female ratio was 7.6:1. Median age was 33 years. The majority of patients were in the $3^{\text {rd }}$ decade of life. Patients below 40 years accounted for $62.79 \%$ of cases. Twenty-four $(55.81 \%)$ patients had hip dislocation. Knee dislocations were the least, accounting for $2.32 \%$ of cases. All cases except three resulted from road traffic accidents (RTAs). None had neurologic deficits. Nineteen (44.23\%) patients had isolated injuries. 76.7\% cases presented in less than 6 hours. All shoulder dislocations were anterior while all elbow dislocations were posterior. All except 3 cases were managed by closed manipulation under general anaesthesia. Two patients died from associated head injury. Fourteen patients discharged against medical advice while recuperating in the ward. Follow-up was however difficult as a significant number did not turn up. Conclusion: Hip dislocation is the commonest variety of traumatic dislocation in our setting. A majority of cases were amenable to closed manipulation and immobilization. Road traffic accidents accounted for the majority.
\end{abstract}

\section{Keywords}

Presentation Pattern, Trauma, Joint Dislocation, Treatment, Effect

\section{Introduction}

Trauma is a serious epidemic of non-communicable disease in the present day. It is now considered a part of the price we pay for the rapid advent of progress in technology. The burden of trauma worldwide is disproportio- 
nately concentrated in lower income countries.

A complete disruption of a joint resulting from trauma is referred to as traumatic dislocation.

Articular surfaces are no longer in contact. When a piece of bone forming part of the articular surface is sheared off, this makes it a fracture-dislocation.

Known causes include road traffic accidents, air crash, falls from height, industrial accidents and sports such as football and wrestling.

When traumatic dislocation occurs, there are other structures that could also fail. This may not be so obvious but would have much more serious consequences. Nerves and blood vessels may also have been stretched far beyond their physiological limit at the time of trauma [1].

Damage to the articular cartilage, joint capsule, ligaments and vascularity of the bone can lead to post traumatic arthritis [2]. Heterotopic ossifications, osteonecrosis, and associated injuries such as fractures of long bones are other known complications.

Dislocations of the elbow are classified according to the direction of displacement. According to the modified Hamilton and Stimson classification [3], radial and ulnar dislocations are either posterior (lateral or medial), medial, lateral, anterior, divergent (antero-posterior or mediolateral), dislocation of radius alone may be anterior, posterior or lateral while dislocation of the ulnar alone could either be posterior or anterior. However, from a practical stand point, about $90 \%$ of elbow dislocations encountered are posterior or posterolateral [3].

Hip dislocations are classified according to the direction of the femoral head displacement: posterior dislocation is by far the commonest variety. Of the large joints, the shoulder is the commonly dislocated, due to a number of factors: the shallowness of the glenoid socket, the extra-ordinary range of movement, underlying conditions such as ligamentous laxity, glenoid dysplasia and the sheer vulnerability of the joint during stressful activities of the upper limb [4].

Most shoulder dislocations are anterior in 95\% - 98\% of cases. The usual location of the displaced humeral head in anterior dislocation is sub-coracoid, followed by sub-glenoid. Intrathoracic and subclavicular dislocations are rare [5]. Anterior shoulder dislocation is usually an injury of adolescents and young adults. Brachial plexus stretch injury is a rare complication; much rarer, is disruption of the axillary vessels with serious catastrophic consequences [6].

Acute dislocations should be reduced as soon as possible. Closed reduction with intravenous analgesia and sedation or general anaesthesia should be attempted first, for most uncomplicated dislocations. Risks of sepsis and further haemorrhage are associated with open surgery. Sepsis affecting a joint could have a very devastating effect, both in the short and long terms.

Reduction manoeuvres have been categorized as traction, leverage or rotational techniques. It is likely that in most cases, all are involved to some degree, because, there is considerable overlap and modification of methods. Open techniques are rarely necessary when managing acute dislocations. Open surgery becomes necessary in cases of failure of closed technique and neglected cases. Other known indications for open reduction include but not necessarily limited to the following:

- If anatomical, concentric reduction cannot be achieved by gentle, closed techniques with the patient under general anaesthesia, interposed soft tissues or osteochondral fragments may contribute to the irreducibility.

- If a stable reduction cannot be maintained. Articular fractures often are unstable and must be reduced and fixed to ensure stability of the reduction.

- If careful evaluation before closed reduction reveals normal neurological function and after reduction a definite complete motor and sensory nerve deficit becomes evident.

- If circulatory impairment distal to the injury is well documented before reduction and persists after reduction. Further assessment of the circulation is essential and should include arteriography.

- If ischemia is persistent, surgical exploration with appropriate management of the vascular injury is indicated.

Injury, as a research problem, has been largely ignored in developing countries [7] [8].

Not many research works of this nature have been carried out in this part of Nigeria, particularly from my centre. Irrua Specialist Teaching hospital (ISTH), Irrua is located along the ever busy Benin-Auchi express road. It receives trauma and related cases from and around the environment. It also serves as the referral centre for all hospitals in the environment. Hence the aim of this study was to evaluate the pattern and management of traumatic joint dislocations as they present to ISTH, Irrua, Edo State of Nigeria. 


\section{Materials and Methods}

The study was carried out at ISTH, Irrua, Edo State of Nigeria—a 375 bedded University Teaching Hospital in South-South, Nigeria.

A review of the Hospital records obtained from the accident and Emergency Unit and Theatres as well as the outpatient departments was undertaken to identify cases of traumatic joint dislocations as seen and managed from $1^{\text {st }}$ January, 2008 to $31^{\text {st }}$ December, 2012.

A proforma was designed to document all relevant data. Ethical clearance was obtained from concerned authority.

The study design was a retrospective descriptive study, involving all patients that met our criteria. Inclusion criteria include inpatients with traumatic dislocations, both males and females of all ages were included. Excluded, were all non-traumatic dislocations, septic dislocations.

Information retrieved were demographic data, aetiology, type of dislocation, interval to presentation, previous treatment, presence of neurological deficits before and after treatment, presence of associated injuries, complications, type of reduction and outcome. These were analysed using simple statistical method of percentages.

\section{Results}

Forty-three patients with traumatic dislocation were treated at ISTH Irrua, Edo State of Nigeria during the fiveyear under review. Thirty-eight of these patients were males while five were females. Male to female ratio was 7.6:1. Median age was 33 years (range 3 - 81 years). Patients below 40 years of age accounted for $62.79 \%$. See Table 1.

Twenty-four (55.81\%) of patients had hip dislocations, one was bilateral. Shoulder dislocations accounted for 23.26\% of cases. Knee dislocation was the least. See Table 2.

All cases, except three followed road traffic accidents (RTAs), two patients fell from heights and one was knocked down by a collapsed mud house. See Table 3.

Isolated acute dislocations were seen in $44.23 \%$, whereas associated injuries were seen in $55.77 \%$.

Long bone fractures constituted the majority of associated injuries. See Table 4.

Associated injuries included blunt chest trauma, rib fractures, blunt abdominal trauma, pelvic, femoral and tibia fractures, head injury, laceration and abrasions. No case of neurologic deficit was seen.

Interval to presentation was variable. See Table 5 . This ranged from $<1 \mathrm{hr}$ in $51.16 \%$ of cases to 3 days in $11.63 \%$.

All shoulder dislocations were anterior while all elbow dislocations were posterior in terms of classification.

All acute dislocations were managed successfully in the theatre under general anaesthesia by closed manipulation, except three cases of hip dislocations.

Open reductions were done after failed attempts at closed manipulation. They were successful.

Table 1. Age and sex distribution of patients.

\begin{tabular}{|c|c|c|c|c|c|c|}
\hline \multirow{2}{*}{ Age } & \multicolumn{2}{|c|}{ Male } & \multicolumn{2}{|c|}{ Female } & \multirow{2}{*}{ Total number } & \multirow{2}{*}{ Total (\%) } \\
\hline & Number & $\%$ & Number & $\%$ & & \\
\hline $1-10$ & 1 & 2.32 & 0 & 0 & 1 & 2.32 \\
\hline $10-20$ & 1 & 2.32 & 0 & 0 & 1 & 2.32 \\
\hline $21-30$ & 15 & 34.88 & 1 & 2.32 & 16 & 37.21 \\
\hline $31-40$ & 10 & 23.26 & 1 & 2.32 & 11 & 25.58 \\
\hline $41-50$ & 3 & 6.98 & 1 & 2.32 & 4 & 9.30 \\
\hline $51-60$ & 4 & 9.30 & 1 & 2.32 & 5 & 11.63 \\
\hline $61-70$ & 1 & 2.32 & 1 & 2.32 & 2 & 4.65 \\
\hline $71-80$ & 2 & 4.65 & 0 & 0 & 2 & 4.65 \\
\hline $81-90$ & 1 & 2.32 & 0 & 0 & 1 & 2.32 \\
\hline Total & 38 & 88.37 & 5 & 11.63 & 43 & 100 \\
\hline
\end{tabular}


Table 2. Pattern of traumatic dislocations.

\begin{tabular}{ccc}
\hline & $\#$ & $\%$ \\
\hline Shoulder dislocations & 10 & 23.26 \\
Elbow dislocations & 4 & 9.30 \\
Hip dislocations & 24 & 55.81 \\
Knee dislocations & 1 & 2.32 \\
Ankle dislocations & 4 & 9.30 \\
Total & 43 & $100 \%$ \\
\hline
\end{tabular}

Table 3. Aetiology of traumatic dislocations.

\begin{tabular}{ccc}
\hline Cause & Number of patients & $\%$ \\
\hline Road traffic accident & 40 & 93.02 \\
Falls from height & 2 & 4.65 \\
Collapsed mud house & 1 & 2.33 \\
Total & 43 & 100 \\
\hline
\end{tabular}

Table 4. Pattern of associated injuries.

\begin{tabular}{ccc}
\hline Associated injuries & $\#$ & $\%$ \\
\hline Blunt chest trauma & 4 & 9.30 \\
Blunt abdominal trauma & 1 & 2.32 \\
Fractures long bones & 8 & 18.60 \\
Head injury (TBI) & 2 & 4.64 \\
Pelvic fractures & 2 & 4.64 \\
Lacerations & 5 & 11.63 \\
Abrasions & 2 & 4.64 \\
\hline
\end{tabular}

Table 5. Intervals to presentations in 43 patients.

\begin{tabular}{ccc}
\hline$<1$ hr & $\#$ & $\%$ \\
$1-6$ hrs & 22 & 51.16 \\
$6-24$ hrs & 11 & 25.58 \\
24 hrs -3 days & 5 & 11.63 \\
& 5 & 11.63 \\
\end{tabular}

Following reduction, elbow and knee joints were immobilized with plaster of Paris splints for three to six weeks. Short collar \& cuff sling for shoulder dislocation and continuous skin traction for those with hip dislocations.

Re-dislocation occurred in one patient who had hip dislocation, twelve days after successful manipulation. This was successfully reduced in the theatre under general anaesthesia. Two patients died from severe head injury associated with acute dislocation.

Fourteen patients discharged against medical advice at various times during their care in the wards. Two patients were referred to other tertiary institutions, on patients' request due to proximity. 
A total of eleven patients came for follow up in the out-patient's clinic over a period of twelve weeks while we could only follow one up for five months in the out-patient's clinic. Others did not turn up for follow-up visits.

One patient, who was initially managed for hip dislocation, had sacral pain on attempting to stand after prolonged sitting, five months after discharge from hospital. Another patient who was managed for acute dislocation of the left shoulder had paraethesia on the dorsum of the left hand.

One patient had osteonecrosis of the head of the left femur.

\section{Discussion}

RTA is responsible for the greatest number of injuries seen in Nigeria as evidenced by hospital statistics and autopsies [9]. 93\% of our cases were due to RTA. Other authors [10]-[14] reported similarly high figures, $62 \%$ $95 \%$. This is explained by the deplorable state of our roads, poor road designs and maintenance. Most vehicles on our roads are old and in disrepair. Some of these issues, such as tyres and brakes, have safety implications. Drunk driving and over-speeding are still common habits in our environment. Falls, though another cause of trauma, featured minimally here, as has been documented in a previous report [15].

Male preponderance in trauma generally is also shown in our study. Male to female ratio was 7.6:1. Our figures are higher than some previous reports such as Swarnkar et al. [10] who reported 3.9:1, Meena et al. [16] and Okaro et al. [11], 1.8:1. Males are more vulnerable and aggressive. They are the bread winners in their families. Those below 40 years of age constituted $62.79 \%$ of our patients. Bhaskara et al. [17] reported $67.42 \%$, being those 18 - 45 years. Jha $\mathrm{N}$ et al. [18] recorded that $53 \%$ of victims were 20 - 40 years. These are consistently high figures. These are the most productive, mobile group and are mainly workers involved in travels, transporting goods and services across the country.

Majority (55.81\%) of our cases were hip dislocations. This is comparable with the report of other authors [17] [19]. They reported $42.86 \%$ and $56 \%$ respectively. This contrast with findings of other authors [11] who recorded dislocations was generally uncommon. Ebong [20] and Meena et al. [16] reported that the most commonly dislocated joint was the shoulder, followed by the elbow.

The rarity of knee dislocations [16] also reflected in our series. It has been implied that the incidence might be higher than recognized because many knee dislocations are reduced at the scene of the injury without subsequent accurate reporting of this diagnosis.

Associated injuries of various severities were seen in 55.77\% of cases. Majority (18\%) were long bone fractures. Enweluzo et al. [19] reported Head injury as the commonest associated injury. People still drive at top speed without using seat belts, making them prone to very serious dislocations with associated injuries. Management of multiple injuries was prioritized, treating the most immediately life threatening injuries first, traditionally following the ABCDE sequence. A-Airway is open and secured. B-Breathing is adequate and oxygen is administered if necessary. C-Circulation: External or internal haemorrhage was controlled expeditiously. D—Neurological disability assessed using the Glasgow Coma Score (GCS). E-Extrication and Immobilization: more complex management is often impractical in an entrapped casualty, so extrication becomes a priority. Limb fractures were immobilized, dislocations were reduced and the limb returned, where possible, to its anatomical position. Limbs were splinted, so as to reduce pain, haemorrhage and minimize damage to neurovascular structures. It is obvious from the above that control of the airway; ventilation and surgical management of haemorrhage were given priority attention while musculoskeletal injuries were initially stabilized followed by definitive treatment. We had some challenges with diagnostic facilities such as lack of computerized tomography (CT) scan machine. This would explain why we lost two patients that had associated head injuries. Provision of essential diagnostic facilities in trauma centres would go a long way to improving service delivery and outcome.

None of the patients had any encounter with the traditional bone setters before presentation. $76.74 \%$ of patients presented in less than 6 hrs after the injury was sustained. This is a clear departure from what used to be. Reasons may not be far-fetched. Severe pain and anxiety that follow such acute injury usually cause them to present at the hospital within a short time. Secondly, and most importantly, motorcycle is the main means of transportation in our environment. They are very accessible, readily available and can ride across terrains that are difficult or almost impossible to cars. Members of the community form a close niche, play the role of 'good Samaritan' to each other. Following an injury, a motorcycle rider is easily and readily mobilised. 
After closed manipulation, joint is immobilized, patients generally feel nothing is being done any more since pain had abated and they discharge against medical advice.

This may attempt to explain why fourteen of our patients discharged against medical advice. Some of these patients we gathered left for the traditional bone-setter's (TBS) home. TBS have an appeal to the citizenry for reasons bothering on cheap cost, alleged and false perception of faster healing and care [21] or weak personal decision making skills [22].

Most dislocations (93\%) were reduced by closed manipulation under general anaesthesia. Previously, other reporters [23] administered intravenous analgesics and diazepam as opposed to general anaesthesia. Reasons for this include but not limited to the following, delay in securing theatre space, shortage of anaesthetists and reluctance of the Nigerian patients to accept general anaesthesia. These constraints are much less pronounced these days.

Open techniques rarely are necessary for acute dislocation [2]. Only 3 (7\%) of our patients had open reduction of acute traumatic dislocation in our series.

Delay in reduction of acute dislocation (>24 hrs) was present in 5 (11.63\%) and this was due to late presentation. This delay can be avoided if the diagnosis were promptly made by the attending physician and reduction or referral made immediately.

Follow up of the patients in this series was difficult. None of the patients attended the out patients clinics after six months. This made the assessment of late complications impossible in this study.

One of the limitations of our study is that inherent to retrospective studies, such as incomplete records and non-uniform documentation of data. This posed problems during data retrieval from records and limited the scope of this work. Computerization and better training of medical records staff would greatly facilitate this kind of research.

\section{Conclusion}

Acute traumatic dislocations do occur in our environment. Road traffic accidents (RTAs) account for the majority of cases. Awareness campaigns on road safety rules targeted at the high risk group (young adult males) such as avoidance of over-speeding, drunk driving, and regular vehicle maintenance should be intensified. Government at all levels should ensure proper road design and regular road maintenance. These would assist in reducing the occurrence of RTAs. Hip dislocation was the commonest. Nearly all cases of traumatic dislocations were successfully managed by closed manipulation and immobilization. Early outcome of treatment was good. Knowledge of the pattern of traumatic joint dislocations would enhance the hospital's preparedness such as provision of highly skilled and trained manpower and ensuring 24 hours trauma operating theatres, delivering effective and efficient health care services and improving patients' outcome.

\section{References}

[1] Russel, R.C.G., Williams, N.S. and Bulstrode, C.J.K. (2000) Fractures and Dislocations, Bailey and Love’s Short Practice of Surgery. 23rd Edition, 320-321.

[2] Diabach, J.A. and Crockarell, J.R. (2003) Acute Dislocations. In: Canale, S.T., Daugherty, K. and Jones, L., Eds., Campbell's Operative Orthopaedics, 10th Edition, Philadephia, 3167.

[3] Moehring, H.D. (1993) Traumatic Dislocations of the Shoulder Girdle and Elbow, Operative Orthopaedics. In: Chapman, M.W., Ed., 2nd Edition, J. B. Lippincott Co., Philadephia, 471-472.

[4] Cole, A., Pavlou, P. and Warwick, D. (2010) Injuries of the Shoulder, Upper Arm and Elbow. In: Solomon, L., Warwick, D. and Nayagam, S., Eds., Apley's System of Orthopaedics and Fractures, 9th Edition, 739-740. http://dx.doi.org/10.1201/b13422-28

[5] Moehring, H.D. (1993) Traumatic Dislocations of the Shoulder Girdle and Elbow, Operative Orthopaedics. In: Chapman, M.W., Ed., 2nd Edition, J. B. Lippincott Co., Philadephia, 460.

[6] Rockwood Jr., C.A., Thomas, S.C. and Matsen III, F.A. (1991) Subluxation and Dislocations about the Glenohumeral Joint. In: Rockwood Jr., C.A., Green, A.P. and Bucholz, R.W., Eds., 3rd Edition, Fracture in Adults, J. B. Lippincott Co., Philadephia.

[7] Aligbe, J.U., Akhiwu, W.O. and Nwosu, S.O. (2002) Prospective Study of Coroners Autopsies in Benin-City, Nigeria. European Journal of Trauma, 365-369.

[8] Zwi, A.B., et al. (1996) Injuries in Developing Countries: Policy Response Needed Now. Transactions of the Royal 
Society of Tropical Medicine and Hygiene, 90, 593-595. http://dx.doi.org/10.1016/S0035-9203(96)90399-5

[9] Krug, E.G., Sharma, G.K. and Loranzo, R. (2000) The Global Burden of Injuries. American Journal of Public Health, 90, 523-526. http://dx.doi.org/10.2105/AJPH.90.4.523

[10] Swankar, M., Singh, P. and Dwiredi, S. (2010) Pattern of Trauma, in Central India. An Epidemiological Study with Special Reference to Mode of Injury. International Journal of Epidemiology, 9, 1.

[11] Okaro, I.O. and Okadugha, C.O. (2006) The Anatomic Pattern of Fractures and Dislocations among Accident Victims in Owerri. Nigerian Journal of Surgical Research, 8, 54-56.

[12] Shadeen, M.A., Mdar, M.A., Al-Kbudary, N., Kham, F.A., Mosalem, A. and Sabet, N. (1990) Pattern of Accidental Fractures and Dislocations in Saudi Arabia. Injury, 21, 347-350.

[13] Patil, S.S., Kakade, R.V., Durgawale, P.M. and Kkade, S.V. (2008) Pattern of Road Traffic Injuries: A Study from Western Maharashtra. Indian Journal of Community Medicine, 33, 56-57. http://dx.doi.org/10.4103/0970-0218.39248

[14] Thanni, L.O.A. and Kehinde, O.A. (2006) Trauma at a Nigerian Teaching Hospital: Pattern and Documentation of Presentation. African Health Sciences, 6, 104-107.

[15] Solagberu, B.A., Adekanye, A.O., Ofoegbu, C.P.K., Kuranga, S.A., Udoffa, U.S., Abdur-Rahman, L.O. and Odelowo, E.O.O. (2002) Clinical Spectrum of Trauma as a University Hospital in Nigeria. European Journal of Trauma, 28, 365-369. http://dx.doi.org/10.1007/s00068-002-1223-y

[16] Meena, R.K., Singh, A.M., Singh, C.A., Chisti, S., Kumar, A.G. and Langshong, R. (2013) Pattern of Fractures and Dislocations in a Tertiary Hospital in North-East India. The Internet Journal of Epidemiology, 11.

[17] Bhaskara, K., Padmanabha, T.S. and Sindhu, N.T. (2014) Pattern of Fractures and Dislocations in a Tertiary Care Hospital, North-East Karnataka. International Journal of Medical Research \& Health Sciences, 3, 847-850. http://dx.doi.org/10.5958/2319-5886.2014.00012.5

[18] Jha, N., Srini, D.R., Roy, G. and Jagadish, S. (2003) Injury Pattern among RTA Cases: A Study from South India. Indian Journal of Community Medicine, 28, 85-90.

[19] Enwelizu, G.O., Giwa, S.O. and Obalum, D.C. (2008) Pattern of Extremity Injuries in Polytrauma in Lagos, Nigeria. Nigerian Journal of Postgraduate Medicine, 15, 6-9.

[20] Ebong, W.W. (1978) The Pattern of Fractures and Dislocation in Western Nigeria. Injury, 9, 221-224. http://dx.doi.org/10.1016/0020-1383(78)90012-8

[21] Thanni, L.O.A. (2000) Factors Influencing Patronage of Traditional Bone Setters. West African Journal of Medicine, 19, 220-224.

[22] Solagberu, B.A. (2005) Long Bone Fractures Treated by Traditional Bone Setters: A Study of Patient’s Behaviour. Tropical Doctor, 35, 106-107. http://dx.doi.org/10.1258/0049475054036797

[23] Alonge, T.O., Ogunlade, S.O. and Idowu, O.E. (2002) Traumatic Dislocation of the Hip Joint-Pattern and Management in a Tropical African Population. West African Journal of Medicine, 21, 288-290. 